\title{
Productos Derivados En Mercados Internacionales
}

\author{
Leoncio Andía Ramos \\ Facultad de Ciencias Contables de la UNMSM \\ Lima - Perú
}

\section{RESUMEN}

La creciente liberalización económica y la apertura de nuestras fronteras económicas a los mercados internacionales están modificando radicalmente el entorno económico- financiero en el que operan las empresas y los ejecutivos. El hecho de que las empresas puedan endeudarse en el exterior, dentro de un sistema de flotación de tipos de cambio internacionales, puede acarrear riesgos para la empresa que antes eran inexistentes: el riesgo cambiario y el riesgo de tasas de interes.

El dinámico desarrollo del mercado financiero internacional ha creado en los últimos años, nuevos instrumentos que permiten reducir la incidencia de los riesgos mencionados sobre las empresas.

Es importante que los ejecutivos de las empresas estén al tanto de los medios que el propio mercado le brinda para poder cumplir mejor su objetivo de maximizar beneficios y minimizar costos sujetos a un nivel de resgo adecuado. Estos medios son llamados «Productos Terminados».

Palabras Clave: Productos Derivados, Bolsa de Valores, Bancos

\section{INTRODUCCIÓN}

El siguiente documento describe una serie de productos derivados los cuales son utilizados en los Mercados Internacionales. Dichos productos se han escogido en base a un criterio de importancia relativa y de simplicidad. Cabe señalar que los productos aquí reseñados han sido descritos de manera suscrita. La intención del presente documento no es analizar de manera detallada cada producto derivado, sino más bien mostrar la diversidad de los mismos.

\section{PRODUCTOS DERIVADOS}

La evolución reciente de la economía peruana viene creando las bases para la aparición de mecanismos de cobertura de riesgos sin afectar la liquidez de los agentes económicos. Los productos derivados son instrumentos financieros más eficientes para cubrir riesgos de mercado, cambiario o de interés.
En la ley general de Bancos permite a bancos y financieras llevar a cabo contratos a plazo «forward contracts « en moneda extranjera. Art.246 y 401 del D.L.770.

\section{Definición}

Los productos derivados son contratos financieros cuyo valor se deriva de algún activo subyacente (divisas, acciones $\mathrm{c}$ comodities); o de algún indicador (como la tasa de interés); o del mercado accionario $u$ otro índice.

\section{Productos Derivados Más Utilizados}

Los productos derivados mas utilizados son:
a.- Contratos a futuras o forwards.
b.- Swaps
c.- Opciones
d.- Caps, floors y collars. 
Participantes en los Productos Derivados

Bancos

Comerciales

DEALERS

\section{Security \\ Firms}

Seguros
Motivaciones de los Productos Derivados

Transferir riesgos no los elimina. El riesgo simplemente se transfiere mediante el contrato original al dealer, éste a su vez puede coberturarse mediante otro contrato con otro dealer, quien por su parte, puede transferírselo a otro dealer a tal vez, a un especulador que desea asumir el riesgo.

\section{DEALER \\ Fuente de ganancia \\ USUARIOS \\ Cobertura}

\section{FUTUROS}

Un ADR se le puede definir como un certificado que representa para sus tendores, la propiedad sobre acciones emitidas por empresas inscritas en el registro de la CONASEV depositadas un Banco custodia local. Estos certificados se negocian en el mercado de valores extranjeros y dan derecho a los poseedores o titulares a recibir dividendos y demás derecho de las acciones

\section{DEALERS}

\section{Bancos}

Pequeños

USUARIOS FINALES

\section{Compañías \\ Industriales}

\section{Fondo de \\ Pensiones}

que respaldan los $\mathrm{ADR}$. Estos $\mathrm{ADR}$ se emiten en dólares y el pago de dividendos también se realiza en dólares.

Hace 12 años que empresas peruanas de gran envergadura inscritas en la Bolsa de Valores de Lima vienen emitiendo los ADR, como Banco de Crédito, Cervecería Backus, Cementos Lima, dentro de otros a fin de poder acceder al mercado de valores de los Estados Unidos para diversificar sus posibilidades de financiamiento y difundir mas su accionariado.

\section{COMOOPERAN LOS ADR}

ADR NO PATROCINADOS: Esos son modos de crear ADR, es generalmente iniciado por uno o mas corredores estadounidense debido al interés de los inversionistas en las acciones de una empresa no estadounidenses. Los corredores solicitan aun banco depositario estadounidense que cree Adra y se concede a la empresa no estadounidense un excepción de las disposiciones sobre información de la ley de valores y bolsa. Los bancos depositarios son compensados 
con las comisiones generados por la emisión y cancelación de certificados y también descuentan comisiones de los pagos de dividendos antes de distribuirlos entre los titulares de ADR.

ADR PATROCINADOS: Se diferencian en que un banco emisor decide promover activamente los ADR de la empresa en los EE.UU. Suele elegirse un solo banco depositario y todos los futuros ADR son emitidos a través de este banco, que asume la función de responsable exclusivo del pago de dividendos, y la distribución de información y la administración del programa. En el caso de los ADR patrocinados estos gastos corren por cuenta del banco depositario o emisor del ADR y no del titular de los $\mathrm{ADR}$ (inversionistas)

\section{NIVELES DE ADR EN EL MERCADO:}

Se encuentran tres niveles de ADR en el mercado a los que se puede acceder

Nivel I

Nivel II

Nivel III

Los dos primeros son para acciones ya existentes en el mercado, y el tercero para la emision de nuevas acciones.

ADR NIVEL I: La emisión de ADR Nivel I no requiere la presentación de información. Pueden ser negociables en el mercado (OTC) over the counter, permite al inversionista extranjero invertir en acciones del mercado local vía $A D R$ nominados en dólares. Asimismo, brindan al emisor nacional la oportunidad de expandir y diversificar la base accionaría e incrementar el precio de su acción como resultado de una demanda y negociación global. El emisor adquiere imagen financiera norteamericano y es considerado hacia programas más avanzados.

ADR Nivel II: Se negocian en New Cork Stock Exchange (NYSE), La american Stock Exchange (AMEX) o la Nacional Associa (NASDAQ). Este nivel proporciona al inversionista una mayor y mejor información sobre el emisor, que está obligado a presentar información anual consolidada según USGAAP que es el sistema contable estadounidense. Este nivel contempla la posibilidad de la expansión de la base accionaría y se compara poder acceder finalmente a la oferta publica. Pero lo que no esta permitido en este mecanismo es el aumento de capital.

Ambos niveles de ADR tienen la misma operatıvidad e involucra la intervencion del inversionista americano, un broker y un banco de ese país, haciendo el papel de banco depositario y de emisor del ADR, el broker, es quien compra las acciones en la bolsa, y un banco custodio donde se depositan las acciones.

ADR Nivel III: Este nivel de ADR permite, el acceso a una más amplia base de inversionistas, razón por la cual el emisor debe realizar una promociona muy amplia y activa a la comunidad de inversionistas (Road Show). Para acceder a este nivel de ADR. Se debe presentar los requerimientos de información a la SEC( USGARRP), para llegar a este nivel de ADR, hay que cumplir la serie de requisitos de la $\mathrm{SEC}$, quien realiza una evaluación severa y rigurosa. 


\section{TIPOS DE OPCIONES:}

Como consecuencia del reordenamiento tanto en el orden económico, político como social, los países de todo el orbe, también han orientado sus políticas a fin de internacionalizar sus economías y entre las mas destacables tenemos los países latinoamericanos, Europa del este parte de Africa, etc. Sientan las bases para que estos pises considerados emergentes desarrollen sus economías y dentro de está su mercado de capitales.

En lo tocante a Perú se están dando las condiciones para el desarrollo y mantenimiento de un mercado de capitales atractivo, entre lo que podemos citar:

- Políticas Económicas de Libre Mercado.

- Liberalización del Mercado de Cambios

- Liberalización del régimen de comercio

- Liberalización de la política de inversión extranjera

- Estabilidad política a través de un congreso elegido democráticamente.

- Privatización de empresas en las que el
Estado tiene participación.

- Crecimiento real del PBI de aproximadamente $4 \%$ con buenas proyecciones al mediano y largo plazo.

- Baja sensible del terrorismo.

Los mercados internacionales de acciones son fuentes importantes de capital, y sitúan al Perú en una plaza atractiva para los inversionistas internacionales entre los que destacan inversionistas institucionales e individuales de Estados Unidos de América.

La diferencia es que una posición larga en opciones, requiere la disponibilidad de caja para pagar las primas, mientras que las posiciones cortas generan caja de manera inmediata.

\section{REFERENCIAS}

1. Toribio Esquivel Obregón: Una visión sobre la economía

2. John Charles Pool - Business \& Economics - 2004 - Conceptos básicos en Economía $\mathrm{El}$ ciclo económico- Alan J. Cage 